\title{
Morphology optimization via side chain engineering enables all-polymer solar cells with excellent fill factor and stability
}

\section{Citation for published version (APA):}

Liu, X., Zhang, C., Duan, C., Li, M., Hu, Z., Wang, J., Liu, F., Li, N., Brabec, C. J., Janssen, R. A. J., Bazan, G. C., Huang, F., \& Cao, Y. (2018). Morphology optimization via side chain engineering enables all-polymer solar cells with excellent fill factor and stability. Journal of the American Chemical Society, 140(28), 8934-8943. https://doi.org/10.1021/jacs.8b05038

DOI:

10.1021/jacs.8b05038

Document status and date:

Published: 18/07/2018

\section{Document Version:}

Accepted manuscript including changes made at the peer-review stage

\section{Please check the document version of this publication:}

- A submitted manuscript is the version of the article upon submission and before peer-review. There can be important differences between the submitted version and the official published version of record. People interested in the research are advised to contact the author for the final version of the publication, or visit the $\mathrm{DOI}$ to the publisher's website.

- The final author version and the galley proof are versions of the publication after peer review.

- The final published version features the final layout of the paper including the volume, issue and page numbers.

Link to publication

\section{General rights}

Copyright and moral rights for the publications made accessible in the public portal are retained by the authors and/or other copyright owners and it is a condition of accessing publications that users recognise and abide by the legal requirements associated with these rights.

- Users may download and print one copy of any publication from the public portal for the purpose of private study or research.

- You may not further distribute the material or use it for any profit-making activity or commercial gain

- You may freely distribute the URL identifying the publication in the public portal.

If the publication is distributed under the terms of Article 25fa of the Dutch Copyright Act, indicated by the "Taverne" license above, please follow below link for the End User Agreement:

www.tue.nl/taverne

Take down policy

If you believe that this document breaches copyright please contact us at:

openaccess@tue.nl

providing details and we will investigate your claim. 


\section{Morphology Optimization via Side Chain Engineering Enables All-Polymer Solar Cells with Excellent Fill Factor and Stability}

Xi Liu, ${ }^{\dagger, \#}$ Chaohong Zhang, ${ }^{\ddagger}$ Chunhui Duan, ${ }^{*}{ }^{\dagger}, \nabla$ Mengmeng Li, $\nabla$ Zhicheng $\mathrm{Hu}^{\dagger}{ }^{\dagger}$ Jing Wang, ${ }^{\S}$ Feng Liu, ${ }^{*}{ }^{\S}$ Ning Li, ${ }^{\ddagger}$ Christoph J. Brabec, ${ }^{\ddagger}{ }^{\wedge}$ René A. J. Janssen, ${ }^{\nabla}$ Guillermo C. Bazan, ${ }^{\#}$ Fei Huang, ${ }^{*}$, and Yong $\mathrm{Cao}^{\dagger}$

${ }^{\dagger}$ Institute of Polymer Optoelectronic Materials and Devices, State Key Laboratory of Luminescent Materials and Devices, South China University of Technology, Guangzhou 510640, P. R. China

${ }^{\ddagger}$ Institute of Materials for Electronics and Energy Technology (i-MEET), Friedrich-Alexander-Universität Erlangen-Nürnberg, Martensstrasse 7, 91058 Erlangen, Germany

${ }^{\nabla}$ Molecular Materials and Nanosystems, Institute for Complex Molecular Systems, Eindhoven University of Technology, P.O. Box 513, 5600 MB Eindhoven, The Netherlands

${ }^{\S}$ Department of Physics and Astronomy, Shanghai Jiao Tong University, Shanghai 200240, P. R. China

${ }^{\#}$ Center for Polymers and Organic Solids, University of California, Santa Barbara, California 93106, United States

^Bavarian Center for Applied Energy Research (ZAE Bayern), Immerwahrstrasse 2, 91058 Erlangen, Germany

KEYWORDS: all-polymer solar cells, side chain engineering, morphology, device performance, stability

ABSTRACT: All-polymer solar cells (all-PSCs) composed of conjugated polymers as both donor and acceptor components in bulk heterojunction photoactive layers have attracted increasing attention. However, it is a big challenge to achieve optimal morphology in polymer:polymer blends. In response, we report herein a new strategy to adjust the nanoscale organization for all-PSCs. Specifically, side chain engineering of the well-known naphthalene diimide (NDI) based polymer N2200 is modulated by introducing a fraction of linear oligoethylene oxide (OE) side chains to replace branched alkyl chains on the NDI units and by synthesizing a series of NDI-based polymer acceptors NOEx, where $x$ is the percentage of OE chain substituted NDI units relative to total NDI units. Compared to the reference polymer NOEo, an OE chain-containing polymer NOE1o offers a much higher power conversion efficiency (PCE) of $8.1 \%$ with a 
record high fill factor (FF) of 0.75 in all-PSCs. Moreover, the NOE1o-based all-PSCs exhibits excellent long-term and thermal stabilities with $>97 \%$ of the initial PCE being maintained after 300 hours aging at $65{ }^{\circ} \mathrm{C}$. This work demonstrates an effective morphology optimization strategy to achieve highly efficient and stable all-PSCs and shows the excellent potential of NOE1o as an alternative to commercially available acceptor polymers N2200.

\section{- INTRODUCTION}

All-polymer solar cells (all-PSCs) composed of a polymeric electron donor and a polymeric electron acceptor have attracted increasing attention. Compared to the extensively studied polymer:fullerene counterparts, all-PSCs may provide critical advantages, including strong light absorption across a wide spectral region, excellent morphological stability and mechanical durability. ${ }^{1-3}$ Moreover, all-PSCs provide unique opportunities to optimize efficiency via tuning and matching optical absorption, energy levels, and the molecular orientation of blend components. ${ }^{2}$ Particularly, the open-circuit voltage $\left(V_{\text {oc }}\right)$ and short-circuit current density $\left(J_{\mathrm{sc}}\right)$ can be significantly increased. These factors have led to the power conversion efficiencies (PCEs) of all-PSCs to rise from $2 \%$ to about $8-10 \%$ over the past five years. ${ }^{4,5}$ All-PSCs nonetheless still lag behind fullerene-based and the emerging small-molecular non-fullerene PSCs in device performance; ${ }^{6}$ very limited all-PSCs offer PCEs over $8 \% .^{5}$ Principally, the unsatisfied device efficiency is due to the difficulty in controlling the bulk-heterojunction ( $\mathrm{BHJ})$ morphology of polymer:polymer blends, resulting in unfavorable charge generation or 
transport. Such suboptimal morphology is exemplified by commonly observed low fill factor (FF) values. Indeed, the FF of all-PSCs seldom exceed o.70, seriously limiting the PCEs of all-PSCs. ${ }^{\mathrm{a}, 5 \mathrm{~d}, 5 \mathrm{e}, \mathrm{ff}_{\mathrm{f}} \mathrm{i}, 7}$

A critical effort to realize optimal blend film morphology and high FF for all-PSCs revolves around the development of novel photoactive layer materials. Benefitting from activities in high-performance fullerene-based PSCs, several polymer donors have been developed that offer multiple options of donor materials. ${ }^{5 \mathrm{a}, 5 \mathrm{~d}, 5^{\mathrm{f}, 8}}$ State-of-the-art polymer acceptors are also very much in demand for efficient and stable all-PSCs. A few promising polymer acceptors have been reported based on fragments that include naphthalene diimide (NDI), ${ }^{8 \mathrm{~b}, 9}$ perylene diimide (PDI), ${ }^{5 \mathrm{~b}, \mathrm{o}}$ bithiophene imide (BTI), ${ }^{11}$ double $\mathrm{B} \leftrightarrow$ bridged bipyridine (BNBP), ${ }^{12}$ and 3,4-difluorothiophene $([2 \mathrm{~F}] \mathrm{T}),{ }^{13}$ which offered PCEs over 6\%. NDI-based polymers have been most widely investigated due to their high electron affinity, electron mobility, and broad optical absorption. The most $\begin{array}{llll}\text { well } & \text { NDI-based } & \text { polymer }\end{array}$ poly[[ $N, N^{\prime}$-bis(2-octyldodecyl)-naphthalene-1,4,5,8-bis(dicarboximide)-2,6-diyl]-alt-5,5 '-(2,2' -bithiophene)] with the commercial name N220o, ${ }^{14}$ which afforded the PCE record of all-PSCs so far..$^{f}$ Based on these considerations, the further development and design of novel polymers based on NDI will not only likely afford promising acceptor materials, but also have an important impact on achieving well controlled $\mathrm{BHJ}$ morphology via rational polymer design.

Herein, we report a new strategy to adjust the nanoscale morphology of the blend film for all-PSCs. A series of new NDI-based polymer acceptors were developed by 
introducing a fraction of linear oligoethylene oxide $(\mathrm{OE})$ side chain to replace the branched alkyl chain on the NDI units. It has been reported that introducing OE side chains onto the photoactive materials can adjust polymer crystallization, charge carrier mobility, and donor:acceptor miscibility in blends. ${ }^{15}$ The polymers are denoted as NOEx, where $x$ stands for the molar percentage of OE chain substituted NDI units relative to the total NDI units. As shown in Figure 1, the molar percentage of the OE chain substituted NDI units is set to be $10 \%, 20 \%$, and $30 \%$, leading to polymers NOE1o, NOE2o, and NOE3o, respectively. Notably, the commercial name of the OE chain-free reference polymer NOEo is N220o. We found that the introduction of OE side chains has little influence on the optical and electrochemical properties, but can substantially change the surface energies and crystallinity in the bulk. Compared to NOEo, NOEıo offers a much higher PCE of $8.1 \%$ with a higher $J_{\mathrm{sc}}$ of $12.9 \mathrm{~mA} \mathrm{~cm}^{-2}$ and a record high FF of 0.75 by using PBDT-TAZ (Figure 1 ) as the donor component of the blend. ${ }^{16}$ This FF is among the highest values reported so far for all-PSCs, approaching the highest FF of o.8o in fullerene-based PSCs, ${ }^{5,17}$ and suggesting the great opportunity of efficiency optimization in all-PSCs. Further investigation revealed that favorable BHJ morphology with proper phase separation and vertical gradient distribution were enabled by NOEıo, which is the main reason for the impressive device performance. Moreover, NOEıo-based all-PSCs demonstrated excellent long-term stabilities and thermal stabilities, exhibiting superiority relative to other high-efficiency solution processed organic photovoltaics. Overall, the results obtained in this work not only provide an effective strategy for morphology and efficiency optimization of all-PSCs, but also 
suggest the outstanding potential of all-PSCs for future technological applications.
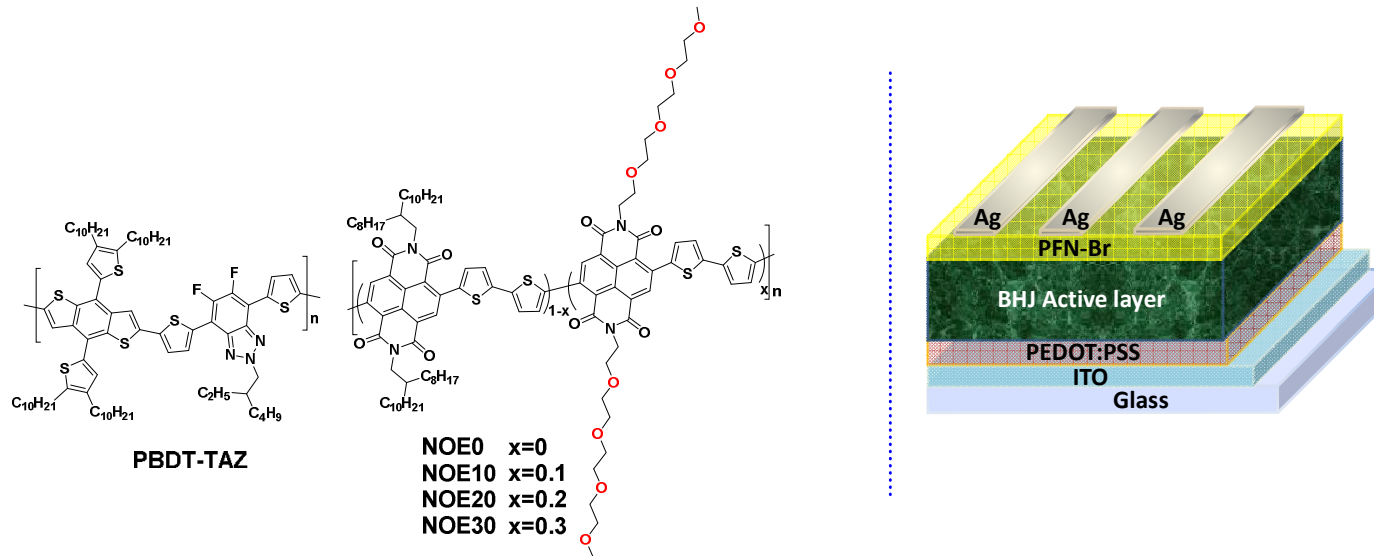

Figure 1. The chemical structures of the donor and acceptor polymers, and the device architecture of all-PSCs employed in this study.

\section{- RESULTS AND DISCUSSION}

\section{Design, Synthesis, and Characterization of NOEx}

Our design for new polymer acceptors is based on N2200, which is a widely used $n$-type polymer due to its high electron affinity and electron mobility. ${ }^{14}$ Different molar percentages of OE chain modified NDI unit were used as the third monomer in the copolymerization reaction, affording four polymers NOEo, NOE10, NOE2o, and NOE3o (Figure 1). These four polymers contain the same conjugated main chain to ensure efficient electron transport, while the OE side chains were anticipated to fine tune miscibility and morphology of the polymer:polymer blend films. The synthetic route (Figure S1, Supporting Information) and detailed procedures for the preparation of the four polymers are described in the Supporting Information. The polymers were synthesized by Stille cross-coupling polymerization from three monomers, 4,9-dibromo-2,7-bis(2-octyldodecyl)benzo[lmn][3,8]phenanthroline-1,3,6,8(2 $\mathrm{H}, 7 \mathrm{H})$-tet 
raone

$(\mathrm{NDIBr}-\mathrm{C} 8 \mathrm{C} 12)$,

4,9-dibromo-2,7-di(2,5,8,11-tetraoxatridecan-13-yl)benzo[lmn][3,8]phenanthroline-1,3,6, $8(2 \mathrm{H}, 7 \mathrm{H})$-tetraone $\quad(\mathrm{NDIBr}-\mathrm{OE}), \quad$ and $\quad 5,5$ ?-bis(trimethylstannyl)-2,2?-bithiophene ( $2 \mathrm{ThSn}$ ) with corresponding feed ratios. The resulting products can be readily dissolved at room temperature in common organic solvents, such as chloroform (CF), chlorobenzene (CB), and 1,2-dichlorobenzene (DCB). Gel permeation chromatography (GPC) measurements in 1,2,4-trichlorobenzene at $150{ }^{\circ} \mathrm{C}$ showed that the polymers have similar number average molecular weights $\left(M_{\mathrm{n}}\right)$ of $\sim 8 \mathrm{o} \mathrm{kDa}$ and polydispersity index (PDI) of $\sim 2.0$; see Table 1 and Figure $\mathrm{S}_{2}$ in the Supporting Information. Introducing OE side chains has little influence on solubilities and molecular weights of the resulting polymers, thereby ensuring a fair comparison for their performance in all-PSCs.

The optical absorption properties of the acceptor polymers (NOEo, NOE1o, NOE2o, and $\mathrm{NOE}_{30}$ ), the donor polymer PBDT-TAZ, and the corresponding blend films were recorded via UV-vis-NIR absorption spectroscopy. The resulting spectra are shown in Figure 2a and Figure $\mathrm{S}_{3}$ (Supporting Information), and relevant data are listed in Table 1. Introducing OE side chains leads to negligible changes relative to the fully alkylated reference polymer NOEo. All polymers show absorption peaks at 707 and $393 \mathrm{~nm}$, with onsets at $\sim 850 \mathrm{~nm}$, leading to optical band gaps $\left(E_{\mathrm{g}}{ }^{\mathrm{opt}}\right)$ estimated to be $1.46 \mathrm{eV}$. The absorption coefficients of all acceptor polymers are similar (Figure S3c, Supporting Information), suggesting that the $\mathrm{OE}$ side chains have little influence on the light absorption of the materials. Considering the narrow bandgap of the acceptor polymers, a wide bandgap polymer (PBDT-TAZ) was selected as the electron donor for all-PSCs, ${ }^{16}$ 
to maximize the light harvesting ability of the blends (Figure $2 \mathrm{a}$ and Figure $\mathrm{S}_{3} \mathrm{~b}$ in the Supporting Information).
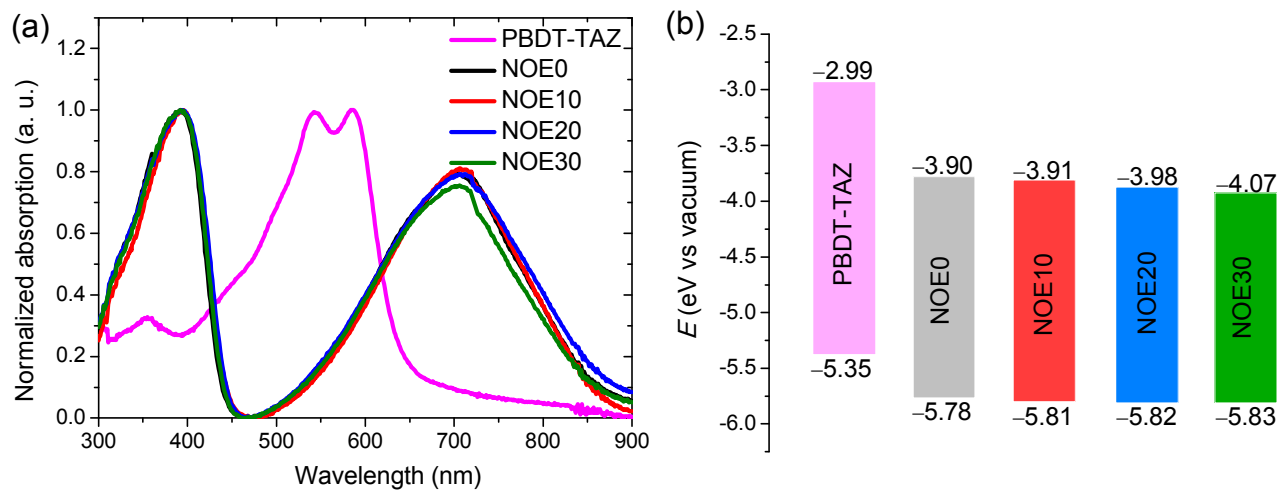

Figure 2. (a) The optical absorption spectra of PBDT-TAZ, NOEo, NOE10, NOE2o, and NOE3o in films; (b) energy levels of PBDT-TAZ, NOEo, NOE1o, NOE2o, and NOE3o.

Table 1. Molecular weights, optical properties, and energy levels of the donor and acceptors polymers.

\begin{tabular}{|c|c|c|c|c|c|c|c|c|c|}
\hline Polymers & $\begin{array}{c}M_{\mathrm{n}} \\
{[\mathrm{kDa}]}\end{array}$ & PDI & $\begin{array}{l}\lambda_{\max }{ }^{\mathrm{a})} \\
{[\mathrm{nm}]}\end{array}$ & $\begin{array}{c}\lambda_{\text {onset }}^{\text {a) }} \\
{[\mathrm{nm}]}\end{array}$ & $\begin{array}{c}E_{\mathrm{g}}^{\text {opt }, \mathrm{b})} \\
{[\mathrm{eV}]}\end{array}$ & $\begin{array}{l}E_{\mathrm{ox}} \\
{[\mathrm{V}]}\end{array}$ & $\begin{array}{l}E_{\mathrm{re}} \\
{[\mathrm{V}]}\end{array}$ & $\begin{array}{c}\left.E_{\mathrm{HOMO}}{ }^{\mathrm{c}}\right) \\
{[\mathrm{eV}]}\end{array}$ & $\begin{array}{c}E_{\text {LUMO }}{ }^{\mathrm{d})} \\
{[\mathrm{eV}]}\end{array}$ \\
\hline PBDT-TAZ & 29 & 2.5 & 586,544 & 641 & 1.93 & 0.83 & -1.53 & -5.35 & -2.99 \\
\hline NOEo & 84 & 1.8 & 707,393 & 847 & 1.46 & 1.26 & -0.62 & -5.78 & -3.90 \\
\hline NOE1o & 83 & 2.0 & 707, 393 & 850 & 1.46 & 1.29 & -0.61 & -5.81 & -3.91 \\
\hline $\mathrm{NOE}_{20}$ & 97 & 2.4 & 707, 393 & 852 & 1.46 & 1.30 & -0.54 & -5.82 & -3.98 \\
\hline $\mathrm{NOE}_{30}$ & 78 & 2.3 & 707,393 & 852 & 1.46 & 1.31 & -0.45 & -5.83 & -4.07 \\
\hline
\end{tabular}

Electrochemical properties were investigated by cyclic voltammetry (CV) (Figure S3d, Supporting Information). Relevant data from these studies are listed in Table 1, and the resulting estimated energy diagram of the polymers is depicted in Figure $2 \mathrm{~b}$. The highest occupied molecular orbital (HOMO) of the OE chains-containing polymers (around $-5.80 \mathrm{eV}$ ) are close to that of NOEo. The lowest unoccupied molecular orbital (LUMO) of the acceptor polymers are slightly lowered by introducing OE side chains as 
compared to the reference polymer NOEo, which might be due to the weak electron-donating effect of the OE side chains to the polymer backbone. ${ }^{15 a}$ Each PBDT-TAZ:NOEx combination has sufficient energy offsets $(>0.3 \mathrm{eV}$ ) for efficient exciton dissociation at donor:acceptor interfaces. ${ }^{18}$

Contact angle measurements were performed to examine the surface energies of the films. ${ }^{19}$ The relevant images are shown in Figure $\mathrm{S}_{4}$ (Supporting Information) and the parameters are summarized in Table $\mathrm{Sr}^{20}{ }^{20}$ By adding more OE chains onto the acceptor polymer, both the water contact angle and oil contact angle become smaller due to the amphiphilicity of OE chains. As a result, introducing more OE chains leads to enhanced contributions from dispersion force but reduced contributions from polar force for the polymer surface energies. Overall, the surface energies of the three OE chain-containing polymers are very similar among each other, but are greatly higher than the reference polymer NOEo. Flory-Huggins interaction parameter $\chi_{\text {donor,acceptor }}$ representing the interaction between the polymer donor and polymer acceptor is a critical evaluation index for polymer:polymer miscibility. ${ }^{21}$ A low $\chi_{\text {donor,acceptor }}$ value means good polymer:polymer miscibility, while a high $\chi_{\text {donor,acceptor }}$ value tends to trigger phase separation in blend films. Estimates for $\chi_{\text {donor,acceptor }}$ can in principle be derived using the empirical equation of $\chi_{\text {donor,acceptor }}=K\left(\sqrt{\gamma_{\text {donor }}}-\sqrt{\gamma_{\text {acceptor }}}\right)^{2}$, where $K$ is a constant, $\gamma_{\text {donor }}$ and $\gamma_{\text {acceptor }}$ are the surface energies of the neat films of donor polymer and acceptor polymer, respectively. ${ }^{21 d}$ As shown in Table S1, the three OE chain-containing polymers lead to similar $\left(\sqrt{\gamma_{\text {donor }}}-\sqrt{\gamma_{\text {acceptor }}}\right)^{2}$ values in blends, which are caused by their similar surface energies. However, the $\left(\sqrt{\gamma_{\text {donor }}}-\right.$ 
$\left.\sqrt{\gamma_{\text {acceptor }}}\right)^{2}$ values are reduced significantly from 0.051 for the reference polymer acceptor NOEo to $\approx 0.020$ for the $\mathrm{OE}$ chain-containing polymers, suggesting that the $\mathrm{OE}$ chain-containing polymers are more miscible with PBDT-TAZ than NOEo. One can therefore expect the phase separation in polymer:polymer blends to be modified by introducing OE side chains on the acceptor polymer. More detailed discussion on the morphology of all-polymer blends will be given in the following parts.

\section{Photovoltaic Properties}

Bulk heterojunction all-PSCs based on the donor polymer PBDT-TAZ and the NOEx polymer acceptors were fabricated with a device structure of ITO/PEDOT:PSS/PBDT-TAZ:NOEx/PFN-Br/Ag. The device performance for PBDT-TAZ:NOEo and PBDT-TAZ:NOE1o was firstly optimized in donor:acceptor weight ratio while keep other conditions constant, which suggested an optimal ratio of 2:1 for the both blends. The PBDT-TAZ:NOEıo blend was further optimized in terms of amount, and type of solvent additive, and thermal annealing at different temperatures to maximize the PCE. The blend films that spin-coated from a solvent mixture of chloroform with $2 \%$ diphenyl ether in volume and further annealed at $160{ }^{\circ} \mathrm{C}$ for 5 min before depositing metal electrode gave the best device performance. These optimal conditions established on PBDT-TAZ:NOEı were then extended to other donor:acceptor blends, and the results from different fabricating conditions are shown in Table $\mathrm{S}_{2}$ in the Supporting Information. Solar cells of PBDT-TAZ:NOEo and PBDT-TAZ:NOE1o with a inverted structure of ITO/ZnO/active layer/ $\mathrm{MoO}_{3} / \mathrm{Ag}$ were also tested, which all produced poorer results (Table $\left.S_{3}\right)$. Current density-voltage $(J-V)$ 
curves and external quantum efficiency (EQE) spectra of the best devices for each polymer acceptor are shown in Figure $3 \mathrm{a}$ and $3 \mathrm{~b}$. Champion device results, average values, and standard deviations of device statistics from twelve independent devices for each acceptor polymer are listed in Table 2.

The PBDT-TAZ:NOEo solar cell shows a PCE of $6.8 \%$ with a $V_{\mathrm{oc}}$ of $0.86 \mathrm{~V}, J_{\mathrm{sc}}$ of 11.4 $\mathrm{mA} \mathrm{cm}{ }^{-2}$, and FF of 0.69 , consistent with the reported results from similar active layer. ${ }^{8 b}$ Compared to the PBDT-TAZ:NOEo solar cell, the performance of PBDT-TAZ:NOE1o solar cell is significantly enhanced and achieves a PCE of $8.1 \%$ with a higher $J_{\mathrm{sc}}$ of 12.9 $\mathrm{mA} \mathrm{cm}{ }^{-2}$, and an FF of 0.75 . To the best of our knowledge, this FF is among the highest values reported for all-PSCs, approaching the highest FF of 0.80 attained with fullerene-based PSCs. ${ }^{5,17}$ The PBDT-TAZ:NOE2o solar cell also offers a PCE of 7.3\%, associated with a $J_{\mathrm{sc}}$ of $11.9 \mathrm{~mA} \mathrm{~cm} \mathrm{~cm}^{-2}$ and an impressive $\mathrm{FF}$ of 0.73 . The PBDT-TAZ:NOE30 solar cell shows a modest PCE of $6.1 \%$ as a result of lower $V_{\text {oc }}$ and $J_{\text {sc }}$ values. Notably, the $V_{\text {oc }}$ of the all-PSCs decreased slightly upon introducing OE side chains onto the acceptor polymers, which agrees with expectations as a result of differences in LUMO levels. Considering the similar absorption coefficients of the four blend films (Figure $S_{3}$, Supporting Information), the significantly higher $J_{\mathrm{sc}}$ and FF of the NOEio-based all-PSCs are most reasonably attributed to optimization of the BHJ morphology. To further demonstrate the potential of NOEıo for all-PSCs, the widely used donor polymer PCEıo was also selected to fabricate all-PSCs. As shown in Figure S5 $_{5}$ and Table $\mathrm{S}_{4}$ (Supporting Information), the PCE1o:NOE1o solar cells show a PCE of 6.4\%, which is higher than the PCE1o:NOEo based device (with a PCE of 5.1\%). Hence, 
NOE1o shows a broad applicability to match different polymer donors. Altogether, these results demonstrate that NOE1o is a promising alternative to the commercial polymer N2200 for the fabrication of all-PSCs.
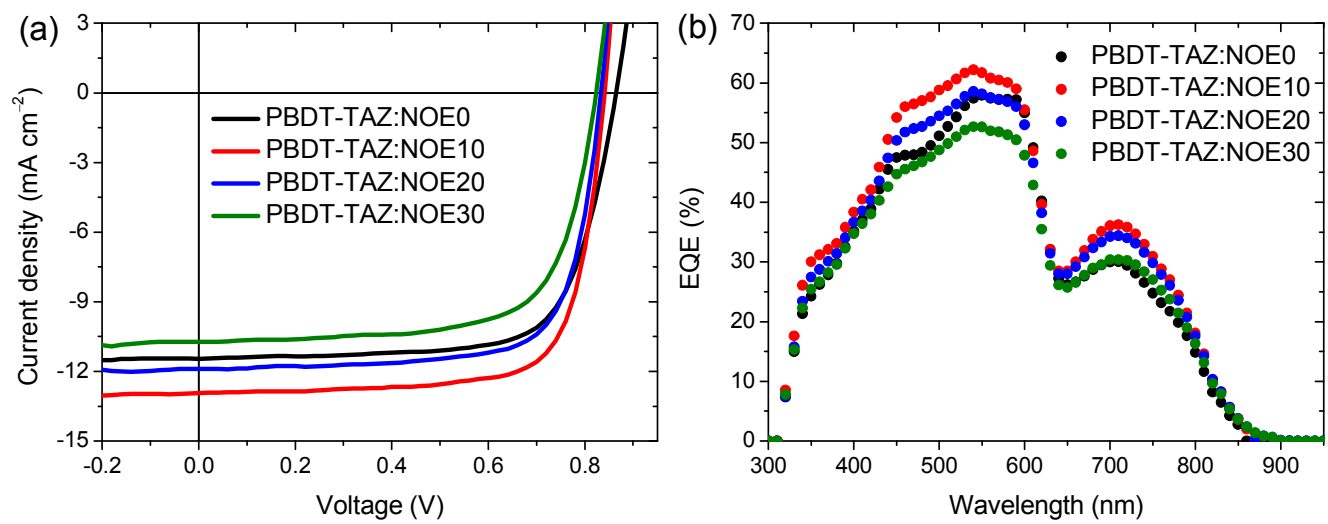

Figure 3. (a) Current density-voltage characteristics of the all-PSCs under AM1.5G illumination at $100 \mathrm{~mW} \mathrm{~cm}{ }^{-2}$; (b) EQE spectra of the corresponding all-PSCs devices.

Table 2. Photovoltaic properties of the all-PSCs under AM1.5G illumination at $100 \mathrm{~mW}$ $\mathrm{cm}^{-2}$.

\begin{tabular}{cccccc}
\hline Active layer ${ }^{\mathrm{a})}$ & $\begin{array}{c}V_{\mathrm{oc}}^{\mathrm{b})} \\
{[\mathrm{V}]}\end{array}$ & $\begin{array}{c}J_{\mathrm{sc}}^{\mathrm{b})} \\
{\left[\mathrm{mA} \mathrm{cm}^{-2}\right]}\end{array}$ & $\begin{array}{c}J_{\left.\mathrm{sc}, \mathrm{EQE}^{\mathrm{c}}\right)} \\
{\left[\mathrm{mA} \mathrm{cm}^{-2}\right]}\end{array}$ & $\mathrm{FF}^{\mathrm{b})}$ & $\begin{array}{c}\mathrm{PCE}^{\mathrm{b})} \\
{[\%]}\end{array}$ \\
\hline PBDT-TAZ:NOEO & 0.86 & 11.4 & 10.8 & 0.69 & 6.8 \\
& $(0.86 \pm 0.01)$ & $(11.2 \pm 0.2)$ & 10.8 & $(0.69 \pm 0.02)$ & $(6.8 \pm 0.1)$ \\
PBDT-TAZ:NOE10 & 0.84 & 12.9 & 12.2 & 0.75 & 8.1 \\
& $(0.84 \pm 0.01)$ & $(12.4 \pm 0.5)$ & & $(0.75 \pm 0.01)$ & $(7.9 \pm 0.2)$ \\
PBDT-TAZ:NOE20 & 0.83 & 11.9 & 11.5 & 0.73 & 7.3 \\
& $(0.83 \pm 0.01)$ & $(11.8 \pm 0.1)$ & & $(0.72 \pm 0.01)$ & $(7.1 \pm 0.2)$ \\
PBDT-TAZ:NOE30 & 0.82 & 10.7 & 10.4 & 0.69 & 6.1 \\
& $(0.82 \pm 0.01)$ & $(10.4 \pm 0.3)$ & & $(0.70 \pm 0.01)$ & $(6.0 \pm 0.1)$ \\
\hline
\end{tabular}

${ }^{a}$ The active layers were optimized with a donor:acceptor weight ratio of 2:1 and spin-coated from a solvent mixture of chloroform with $2 \%$ diphenyl ether in volume and further annealed at $160{ }^{\circ} \mathrm{C}$ for $5 \mathrm{~min}$ before electrode deposition; ${ }^{\text {b) }}$ The average values and standard deviation of device statistics from 12 devices are listed in the parentheses; ${ }^{c)}$ photocurrents obtained by integrating the EQE curves.

The EQE spectra of the all-PSCs are shown in Figure 3b. The all-PSCs show broad 
photo-response over the spectral region from 300 to $850 \mathrm{~nm}$, which is consistent with the absorption of the blend films. The EQE curves also suggest photocurrent contributions from both donor and acceptors polymers. EQEs peaked at $\approx 550 \mathrm{~nm}$ mainly originate from electron transfer from PBDT-TAZ to the polymer acceptors, and the EQEs peaked at $\approx 710 \mathrm{~nm}$ are attributed to hole transfer from the polymer acceptors to PBDT-TAZ. The photocurrents obtained by integrating the EQE curves are slightly lower than the $J_{\mathrm{sc}}$ measured from the $J-V$ curves with a mismatch within $5 \%$. Similar to N2200, the low absorption coefficient of NOEx in low energy region limit the EQEs and the $J_{\mathrm{sc}}$ in solar cells. Further research toward higher PCEs of all-PSCs should thus focus on improving the absorption coefficient in near infrared region, such as adding a narrow bandgap polymer with intense light absorption to form ternary solar cells.

\section{Charge Generation, Transport, and Recombination}

Photoluminescence (PL) quenching experiments were conducted to investigate photoinduced charge transfer processes at the donor/acceptor interfaces. Pure films of PBDT-TAZ, NOEo, NOE1o, NOE2o, NOE3o, and the four corresponding blend films were excited at $530 \mathrm{~nm}$ to study electron transfer from excited PBDT-TAZ to acceptor polymers and at $710 \mathrm{~nm}$ to study hole transfer from excited acceptor polymers to PBDT-TAZ. As shown in Figure S6a (Supporting Information), PBDT-TAZ:NOE1o shows a PL quenching efficiency (96\%) that is higher than for the other three blends $(76 \%$ for PBDT-TAZ:NOEo, 90\% for PBDT-TAZ:NOE20, and 90\% for PBDT-TAZ:NOE3o), suggesting the most efficient electron transfer from the excited donor to NOE1o. When excited at $710 \mathrm{~nm}$, the PBDT-TAZ:NOE1o film also shows a higher PL quenching 
efficiency (89\%) (83\% for PBDT-TAZ:NOEo, 81\% for PBDT-TAZ:NOE2o, and 81\% for PBDT-TAZ:NOE30; Figure S6b in the Supporting Information), suggesting the most efficient hole transfer from the excited acceptor to NOE1o. The most efficient electron and hole transfer efficiencies in the PBDT-TAZ:NOE1o blend film agree well with the highest EQE and $J_{\mathrm{sc}}$ in all-PSCs.

We then studied the exciton dissociation probability $P(E, T)$ of the solar cells. ${ }^{22}$ Figure 4a shows the photocurrent density $\left(J_{\mathrm{ph}}, J_{\mathrm{ph}}=J_{\mathrm{L}}-J_{\mathrm{D}}\right.$, where $J_{\mathrm{L}}$ and $J_{\mathrm{D}}$ are the light and dark current density, respectively) versus effective voltage ( $V_{\text {eff, }} V_{\text {eff }}=V_{\mathrm{o}}-V_{\mathrm{a}}$, where $V_{\mathrm{o}}$ is the voltage when $J_{\mathrm{ph}}$ is equal to o, and $V_{\mathrm{a}}$ is the applied bias voltage) of the all-PSCs. The $P(E, T)$ is defined by normalizing $J_{\mathrm{ph}}$ with the saturation photocurrent density $\left(J_{\text {sat }}\right)$. Under short-circuit conditions, the all-PSCs show $P(E, T)$ values over $93 \%$, suggesting efficient exciton dissociation for all devices. The highest $P(E, T)$ value of $96 \%$ was produced by NOE1o-based device, consistent with the highest $J_{\text {sc }}$ and EQE of the PBDT-TAZ:NOE1o devices. It is worth pointing out that the difference in $P(E, T)$ for the various devices is small, so the differences in $J_{\mathrm{sc}}$ and EQE are probably rather determined by charge recombination than by generation.
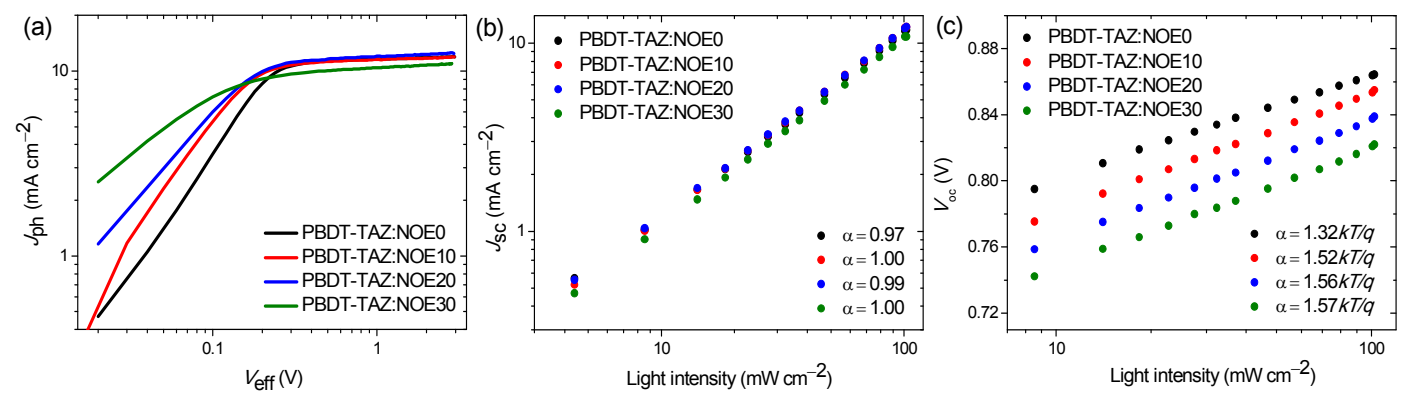

Figure 4. (a) Photocurrent density $\left(J_{\mathrm{ph}}\right)$ versus effective voltage $\left(V_{\text {eff }}\right)$ curves of the all-PSCs; (b) light intensity dependence of $J_{\mathrm{sc}}$ of the all-PSCs; (c) light intensity dependence of $V_{\text {oc }}$ of the all-PSCs. 
The device performance, especially $J_{\mathrm{sc}}$ and FF, is also greatly affected by charge transport and recombination. The charge carrier mobility in pure acceptors and their blend films were thus measured from single carrier devices by fitting the $J-V$ data to a space-charge-limited current model. The results are summarized in Table $\mathrm{S}_{5}$ (Supporting Information). In pure polymer films, the four NOEx polymers exhibit similar electron mobilities $\left(\mu_{\mathrm{e}}\right)$ of $\approx 4.0 \times 10^{-5} \mathrm{~cm}^{2} \mathrm{~V}^{-1} \mathrm{~s}^{-1}$. After blended with PBDT-TAZ, the NOE10-, NOE20-, and NOE3o-based blend films exhibit $\mu_{\mathrm{e}}$ of 1.6, 1.5, and $1.2 \times 10^{-4}$ $\mathrm{cm}^{2} \mathrm{~V}^{-1} \mathrm{~s}^{-1}$, respectively, which are considerably higher than the NOEo-based film $(5.7 \times$ $\left.10^{-5} \mathrm{~cm}^{2} \mathrm{~V}^{-1} \mathrm{~s}^{-1}\right)$. Additionally, the four blend films show very similar hole mobilities $\left(\mu_{\mathrm{h}}\right)$ in a range from $2.1 \times 10^{-4}$ to $1.5 \times 10^{-4} \mathrm{~cm}^{2} \mathrm{~V}^{-1} \mathrm{~s}^{-1}$. Correspondingly, the $\mu_{\mathrm{e}} / \mu_{\mathrm{h}}$ ratios for NOEo, NOE1o, NOE20, and NOE3o blend films are 0.3, 1.0, o.9, and o.8, respectively. The optimally balanced electron/hole transport in the PBDT-TAZ:NOE1o blend contributes to the highest $\mathrm{FF}$ and $J_{\mathrm{sc}}$ in solar cells

Charge recombination mechanisms of the all-PSCs were examined through measurements of the light intensity dependence of the $J_{\mathrm{sc}}$ and $V_{\mathrm{oc}}$. The correlation of the $J_{\mathrm{sc}}$ and the light intensity $\left(P_{\text {light }}\right)$ obeys the power-law $J_{\mathrm{sc}} \propto P_{\text {light }}{ }^{\alpha}$, where $\alpha$ is an exponential factor that should be equal to 1 if the bimolecular recombination of the device is negligible. ${ }^{23}$ As shown in Figure $4 b, \alpha$ values from the fitted line for the all-PSCs based on NOEo, NOE1o, NOE2o, and NOE3o are 0.97, 1.00, 0.99, and 1.0o, respectively, indicating negligible bimolecular recombination in these devices. The slope of $V_{\text {oc }}$ versus $\ln \left(P_{\text {light }}\right)$ curve reflects the property of charge recombination at open 
circuit condition. The slope will be $1.0 k T / q$ when bimolecular recombination is dominant, where $k$ is the Boltzmann constant and $T$ is the temperature. ${ }^{23}$ As shown in Figure 4c, the all-PSCs based on NOEo, NOE1o, NOE2o, and NOE3o exhibit a slope of $1.32 \mathrm{kT} / \mathrm{q}, 1.52 \mathrm{kT} / \mathrm{q}, 1.56 \mathrm{kT} / \mathrm{q}$, and $1.57 \mathrm{kT} / \mathrm{q}$, respectively. These observations suggest that the OE chain-containing acceptor polymers can reduce bimolecular recombination in all-PSCs.

To evaluate the efficiency of collected carriers per incident absorbed photon upon introducing OE chains onto polymer acceptor, the internal quantum efficiencies (IQEs) of the PBDT-TAZ:NOEo and PBDT-TAZ:NOE1o solar cells were calculated from their EQEs and the total fraction of absorbed photons, which was determined from the wavelength dependent refractive index and extinction coefficients followed by optical modelling of the entire device stack. As shown in Figure 5, the PBDT-TAZ:NOEıo solar cell shows higher IQEs than PBDT-TAZ:NOEo cell in the main absorption range of $400-700 \mathrm{~nm}$, suggesting that the absorbed photons are more efficiently converted into free charge carriers in NOEıo-based device. For both blends, the contributions of the PBDT-TAZ and NOEx to the IQE are similar, evidencing both components provide equal contributions to photocurrent after absorbing light. 


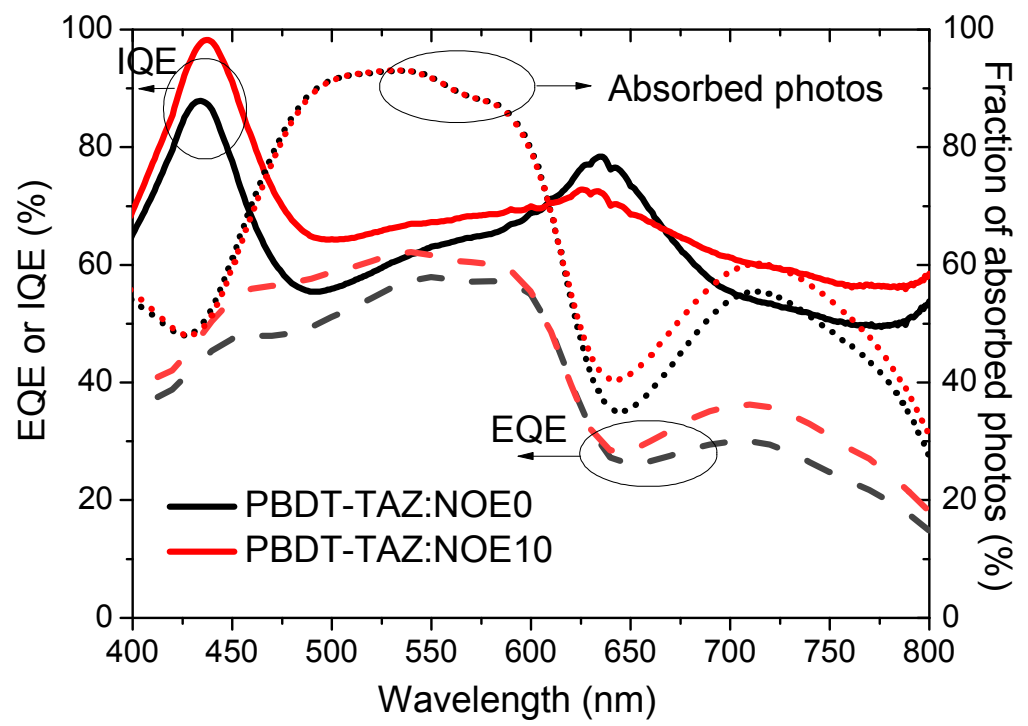

Figure 5. Internal quantum efficiency (IQE) of PBDT-TAZ:NOEo and PBDT-TAZ:NOE1o based devices (solid lines), EQE curves of the two devices (dash lines), and absorption of the two blend films (short dot lines). The peaks in the IQEs at $\sim 640 \mathrm{~nm}$ are possibly due to an underestimation of the fraction absorbed photons.

\section{Morphology}

The structural order of pure and blended thin films were investigated by grazing incidence wide-angle $x$-ray diffraction (GIWAXS) method. The $2 \mathrm{D}$ diffraction images and line-cut profiles are shown in Figure S8 (Supporting Information). These studies show that both PBDT-TAZ and the NOE polymer series take a preferred face-on orientation relative to the substrate. PBDT-TAZ showed a (100) diffraction peak in the in-plane direction at $\sim 0.25 \AA$. The crystal coherence length (CCL) obtained by use of the Scherer equation yielded a value of $12.1 \mathrm{~nm}$. Notably, for the NOE polymer series the relative crystallinity decreases as the content of hydrophilic OE side chain increases. NOEo shows a quite sharp (100) diffraction at $\sim 0.25 \AA$, with a CCL of $41.8 \mathrm{~nm}$. 
Introducing hydrophilic side chains leads to a reduction of (100) peak intensity and full-width-at-half-maximum (FWHM). NOE1o, NOE20, and NOE3o yield CCLs of 36.9, 27.3, and $14.6 \mathrm{~nm}$, respectively. The sharp peak at $0.45 \AA$ in the in-plane direction was assigned to the (oo1) plane of NOE polymer series. Thus quite rigid backbone and well-ordered side chains can be resolved. It should also be noted that adjacent to this peak comes the (200) diffraction from NOE polymers, which decreases in intensity as the hydrophilic side chain content increases. Pi-pi stacking features can be well-resolved in the out of plane direction. PBDT-TAZ shows a diffraction peak at $1.73 \AA$, while the NOE polymer series shows diffraction peaks at $1.62 \AA$ A BHJ thin films (Figure 6) show diffraction features that are a combination of features characteristic of PBDT-TAZ and the NOE polymer series. The similar position of (100) diffraction from donor and acceptor polymers made it difficult to evaluate the crystal coherence length of each species. Yet the overall FWHM gradually increased from PBDT-TAZ:NOEo to PBDT-TAZ:NOE3o blends (size change from 32 to $21 \mathrm{~nm}$ ). The well-developed (oo1) peak from NOE polymers indicated that they form good ordered structures in blends. The correlation length of (oo1) peak was estimated to be $30-40 \mathrm{~nm}$ for PBDT-TAZ:NOE blends, which reduces slightly with more hydrophilic OE side chains. Thus good chain alignment in solid-state packing is expected. Weak (300) diffractions were seen from NOE polymers, and thus the good crystallinity and crystal quality should form the framework of phase-separated structure in BHJ blends. The pi-pi stacking of $\mathrm{BHJ}$ blended film is located at 1.66-1.68 Å, which summarized packing features from both donor and acceptor polymers. It should be noted that PBDT-TAZ:NOEio blends show 
the smallest packing at $1.66 \AA$, indicating the highest contribution from NOEıo polymers, and thus best structural order for acceptor polymers in BHJ blends.
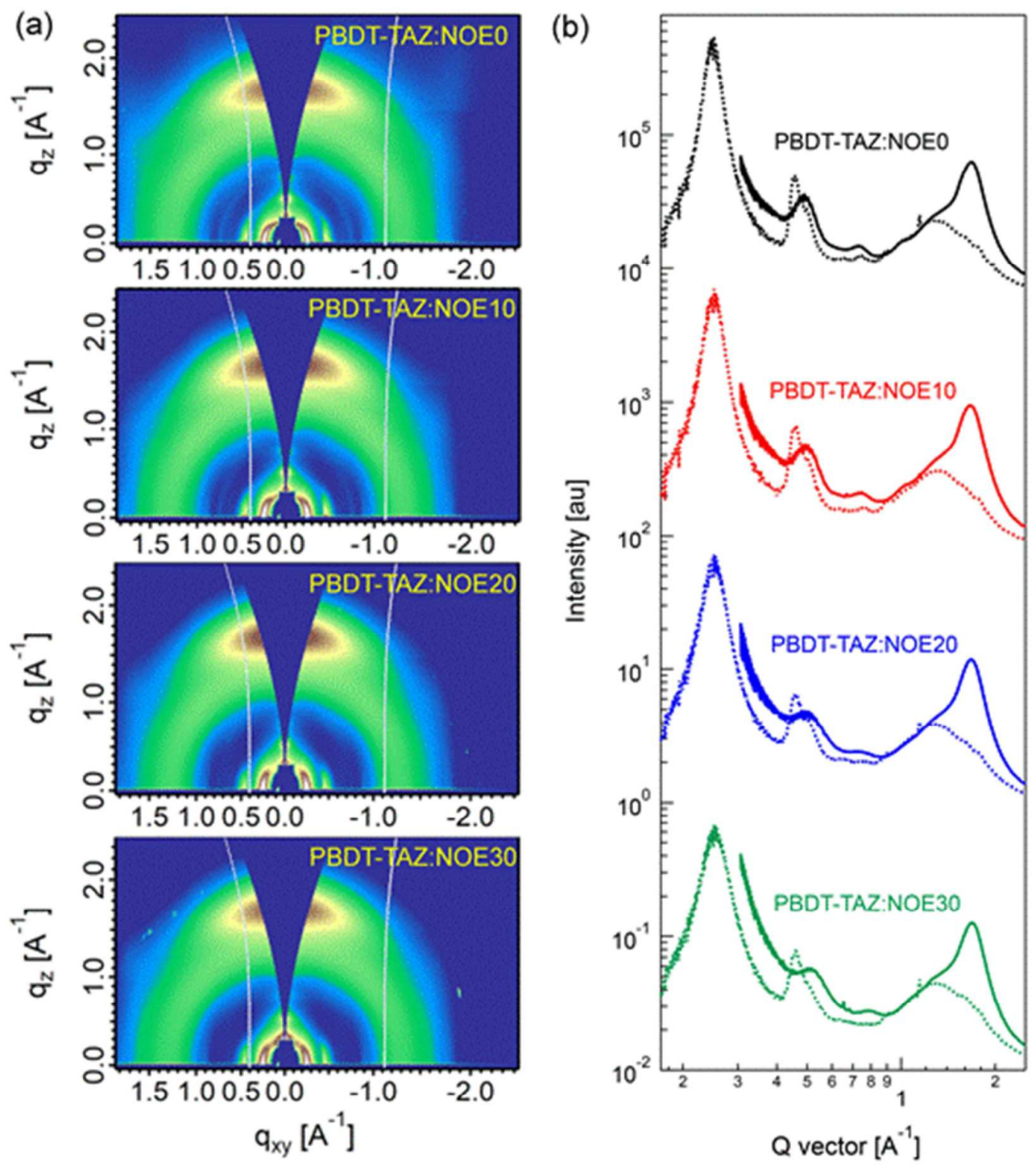

Figure 6. GIWAXS of PBDT-TAZ:NOEx BHJ films. Diffraction patterns (a), and line-cut profiles (b) (solid line: out-of-plane line-cut profiles; dotted line: in-plane line-cut profiles).

The morphology of the active layers was studied by transmission electron microscopy (TEM), see Figure 7. Films based on NOEo and NOEıo blends show 
whiskers with diameters of tens of nanometers and lengths of hundreds of nanometers, which are roughly aligned radially, as expected from centrifuge force of spin coating. NOE2o based blend films showed blurred whiskers, and these features became not obvious for $\mathrm{NOE}_{3}$ o based blends. These whiskers showed size scales similar to NOE polymers by GIWAXS characterizations. These ordered structures are favorable to efficient charge transport in blend films, and thus contribute to the excellent FF and higher $J_{\mathrm{sc}}$ in all-PSCs device. Moreover, such blend morphology is also in favor of long-term stability of the devices, which will be discussed later. TEM images also showed aggregated species with different color depth with roughly $100 \mathrm{~nm}$ phase-separated length scales. These features were observed in resonant soft x-ray scattering (RSoXS) experiment (Figure S9, Supporting Information) with diffuse humps. NOE1o and NOE2o based blends showed the least scattering intensity, which indicates better film uniformity. Such a feature added to whiskers morphology can be used to explain the improved device performance with the novel polymer acceptors.
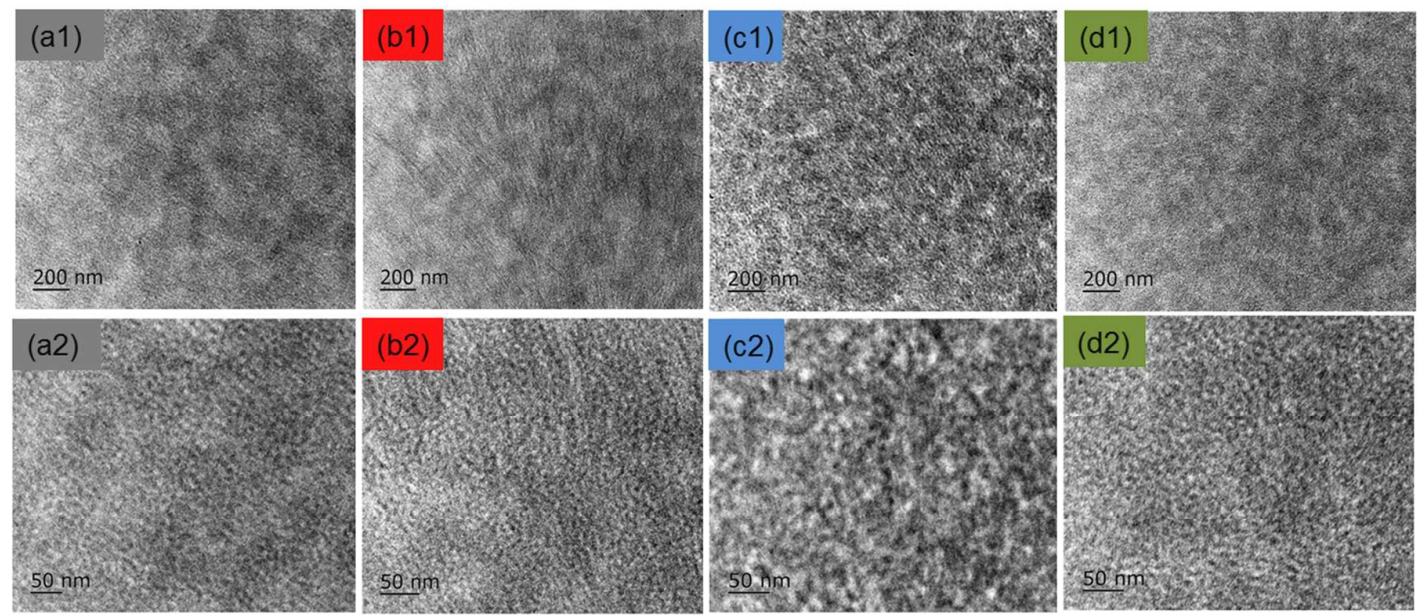

Figure 7. TEM images of the PBDT-TAZ:NOEx blend films based on NOEo (a1,az), NOE1o (b1,b2), NOE2o $\left(\mathrm{cl}_{1}, \mathrm{c}_{2}\right)$, and $\mathrm{NOE}_{3} \mathrm{O}\left(\mathrm{d}_{1}, \mathrm{~d}_{2}\right)$, respectively. The scale bar is $200 \mathrm{~nm}$ for a1, b1, c1, and d1, and $50 \mathrm{~nm}$ for a2, b2, c2, and d2. 
The importance of the nano whisker morphology in PBDT-TAZ:NOEıo blends were further revealed by photoinduced force microscopy (PiFM). ${ }^{24}$ By imaging at the characteristic Fourier transform infrared (FT-IR) wavenumber corresponding to absorption peaks of donor and acceptor materials, PiFM showed better resolution power to spatially map nanoscale patterns of specific chemical components in blend films..$^{5,25}$ As shown in Figure S1o (Supporting Information), we selected the absorption peak at $1758 \mathrm{~cm}^{-1}$ in FTIR for PBDT-TAZ imaging and the peak at $1668 \mathrm{~cm}^{-1}$ for NOEo and NOE1o imaging in PiFM measurements. As shown in Figure 8a1 and 8b1, when selectively imaged at $1758 \mathrm{~cm}^{-1}$ by PiFM, PBDT-TAZ phase was highlighted, which homogenously distributes over the entire films, forming a good hole transporting media. Figure 8a2 and 8b2 present the selective imaging of the blend films at $1668 \mathrm{~cm}^{-1}$, where NOE polymer acceptors were highlighted. Figure $8 \mathrm{a} 3$ and $8 \mathrm{~b}_{3}$ display the combinations of the PiFM images at 1758 and $1668 \mathrm{~cm}^{-1}$ for PBDT-TAZ:NOEo and PBDT-TAZ:NOE1o, respectively. PiFM images with a large length scale demonstrated in Figure 8a4 and 8b4 revealed nano whiskers with diameters of tens of nanometers and length of hundreds of nanometers. Moreover, in NOE1o-based blends these nano whiskers were better separated with less agglomerated bundles. Thus there are more internal interfaces for PBDT-TAZ:NOE1o blends, giving rise to improved $J_{\text {sc }}$. It is thus clear that NOE1o can lead to the formation of not only more proper phase separation in all-polymer blends but also more crystalline polymer fibers with more clear grain boundaries, which ultimately contribute to enhanced charge transport and solar cell performance. 

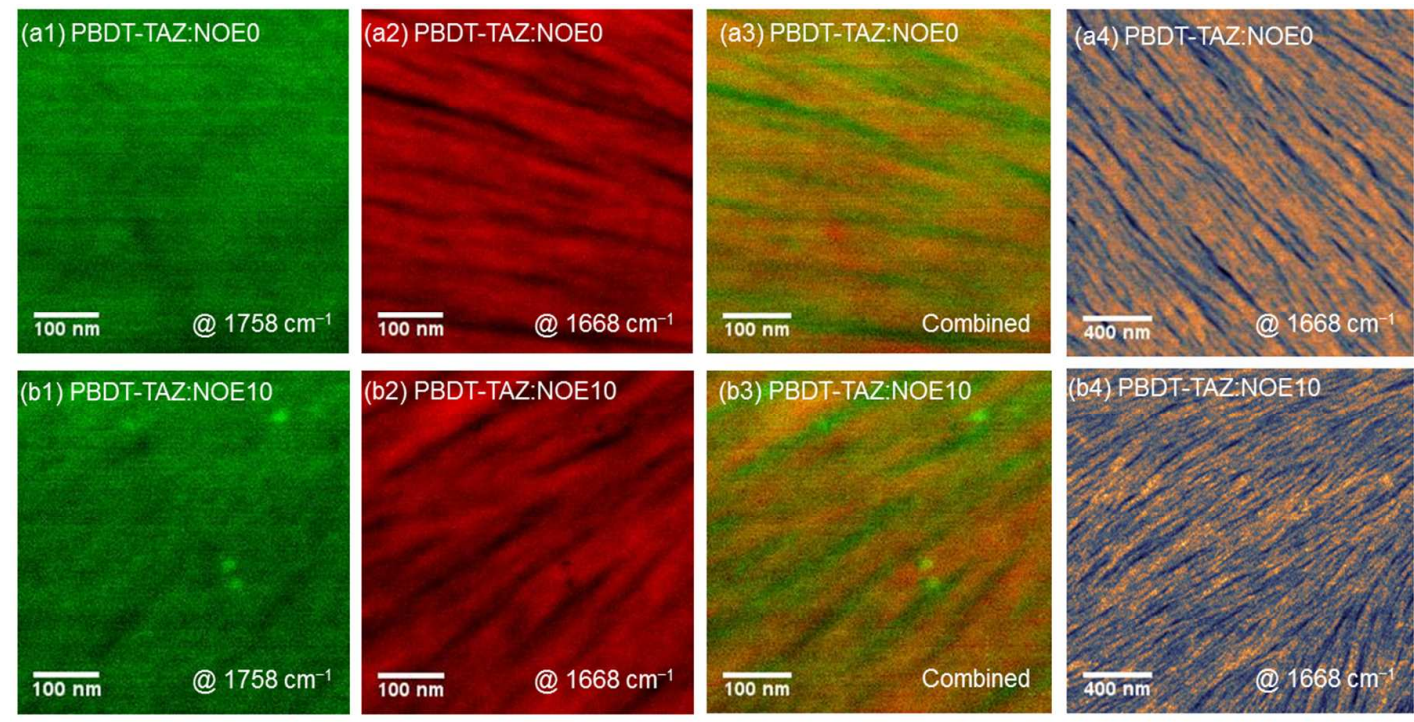

Figure 8. PiFM images of the two blend films. (a1) PBDT-TAZ:NOEo and (b1) PBDT-TAZ:NOE1o imaged at $1758 \mathrm{~cm}^{-1}$; (a2) PBDT-TAZ:NOEo and (b2) PBDT-TAZ:NOE1o imaged at $1668 \mathrm{~cm}^{-1}$; (a3) PBDT-TAZ:NOEo and (b3) PBDT-TAZ:NOE1o by combining the images mapped at 1758 and $1668 \mathrm{~cm}^{-1}$; (a4) PBDT-TAZ:NOEo and (b4) PBDT-TAZ:NOE1o imaged at $1668 \mathrm{~cm}^{-1}$ with larger length scale. The scale bars are shown in each picture.

Secondary ion mass spectrometry (SIMS) is a sensitive surface analytical technique, which can be used to determine the elemental composition of the samples as function of depth. As shown in Figure $\mathrm{S}_{11}$ (Supporting Information), the counts of ${ }^{13} \mathrm{C}$ and ${ }^{16} \mathrm{O}$ in the PBDT-TAZ:NOEo and PBDT-TAZ:NOEıo blend films were recorded over sputtering time. In the two blend films, we can probe relative vertical phase distribution using the ${ }^{16} \mathrm{O} /{ }^{13} \mathrm{C}$ count ratios as oxygen element is characteristic for the acceptor polymers. Figure 8a shows the ${ }^{16} \mathrm{O} /{ }^{13} \mathrm{C}$ count ratios for PBDT-TAZ:NOEo and PBDT-TAZ:NOE1o, which were calculated from Figure Sira and Silb (Supporting Information), respectively. In order to make an accurate comparison, a curve of $\left({ }^{16} \mathrm{O} /{ }^{13} \mathrm{C}\right) \times 1.2$ count ratio was used for PBDT-TAZ:NOEo because, statistically, the oxygen population of NOE1o is 1.2 times that of NOEo. Within the first $40 \mathrm{~nm}$ depth range of the blend films, the ${ }^{16} \mathrm{O} /{ }^{13} \mathrm{C}$ ratios 
of PBDT-TAZ:NOE1o are higher than the $\left({ }^{16} \mathrm{O} /{ }^{13} \mathrm{C}\right) \times 1.2$ ratios of PBDT-TAZ:NOEo, indicating that NOE1o is more prone to be enriched at the active layer surface compared to NOEo. Conversely, for the last $40 \mathrm{~nm}$ depth range of the blend films, the ${ }^{16} \mathrm{O} /{ }^{13} \mathrm{C}$ ratios of PBDT-TAZ:NOE1o are lower than the $\left({ }^{16} \mathrm{O} /{ }^{13} \mathrm{C}\right) \times 1.2$ ratios of PBDT-TAZ:NOEo, suggesting NOE1o is less enriched at the bottom of the active layer than NOEo. In this case, the PBDT-TAZ:NOE1o blend shows more proper vertical phase distribution with the device structure of ITO/PEDOT:PSS/active layer/PFN-Br/Ag, which ultimately facilitates charge extraction and reduces charge recombination; features that combine to produce a higher FF and $J_{\mathrm{sc}}$. Combined with TEM images, PiFM results, and SIMS analysis, we can establish three-dimensional microstructure schematics of the PBDT-TAZ:NOEo and PBDT-TAZ:NOE1o blends (Figure 9b and 9c), which describe the polymer ordering, phase separation and vertical phase gradation of the two blend films.

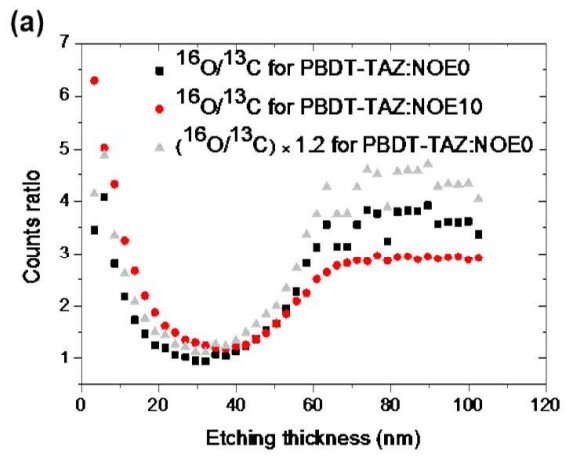

(b)

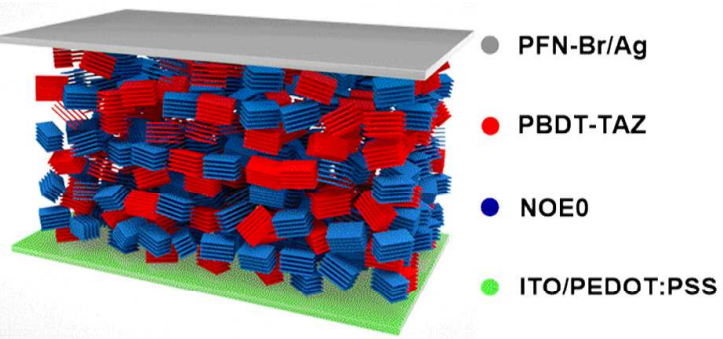

(c)

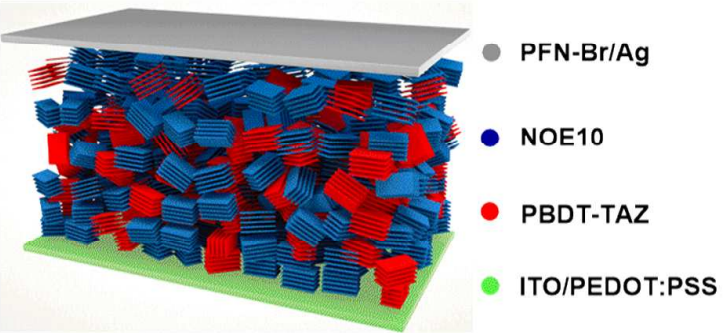

Figure 9. (a) ${ }^{19} \mathrm{~F} /{ }^{16} \mathrm{O}$ counts ratios in the two blend films over thickness; (b) schematic illustration of PBDT-TAZ:NOEo blend film; (c) schematic illustration of PBDT-TAZ:NOE1o blend film. 


\section{Device Stability}

It has been previously established that a BHJ morphology with high miscibility of donor phase and acceptor is beneficial to achieve high device stability. ${ }^{26}$ We thus expect that PBDT-TAZ:NOEıo blend will exhibit improved device stability in all-PSCs. Accordingly, device stabilities of the PSCs made from the same donor PBDT-TAZ but different acceptors of NOEo, NOEıo, PCBM, and ITIC were tested and are compared in Figure 10a and S12 (Supporting Information). NOEo (N220o), PCBM, and ITIC have been widely used as electron acceptors for organic photovoltaics. Devices were stored in nitrogen-filled glovebox at room temperature under dark conditions. The performances of these devices upon different storage time are shown in Figure S12 (Supporting Information). After 400 hours storage under dark conditions, the PBDT-TAZ:NOEıo device retains $95 \%$ of its initial PCE. In contrast, PBDT-TAZ:NOEo device retains $85 \%$ of its initial PCE after 200 hours, and PBDT-TAZ:ITIC and PBDT-TAZ:PCBM retain less than $70 \%$ of their initial PCE after 100 hours. These results clearly demonstrate the superiority of NOEıo over other electron acceptors in device stability.

Further, the device stability of PBDT-TAZ:NOEıo was compared with two highly efficient solar cells PBDB-T:ITIC ${ }^{27 \mathrm{a}}$ and PCE11:PCBM ${ }^{27 \mathrm{~b}}$ under continuous thermal aging. The normalized device performances of these solar cells with $65{ }^{\circ} \mathrm{C}$ thermal aging are shown in Figure $10 \mathrm{~b}$, and the detailed device parameters $\left(V_{\mathrm{oc}}, J_{\mathrm{sc}}\right.$, and $\left.\mathrm{FF}\right)$ are provided in Figure $\mathrm{S}_{14}$ (Supporting Information). After 300 hours continuous thermal aging at $65{ }^{\circ} \mathrm{C}$, the PBDT-TAZ:NOE1o device retains $>97 \%$ of its initial PCE without burn-in efficiency loss at all. The burn-in free feature of PBDT-TAZ:NOEı device can be 
attributed to its stable blend morphology. ${ }^{26 \mathrm{~b}}$ However, the PBDB-T:ITIC and PCE11:PCBM devices show significant burn-in efficiency losses with less than $80 \%$ of their initial PCEs being retained after 300 hours aging for PBDB-T:ITIC device and 100 hours aging for PCE11:PCBM device. Overall, the all-PSCs based on NOE1o show excellent storage lifetime and thermal stability. In particular, the PBDT-TAZ:NOE1o cell exhibits much better thermal stability than state-of-the-art fullerene- and small molecular non-fullerene-based solar cells, demonstrating a significant advantage of NOE1o as a promising electron acceptor for practical applications of polymer solar cells.
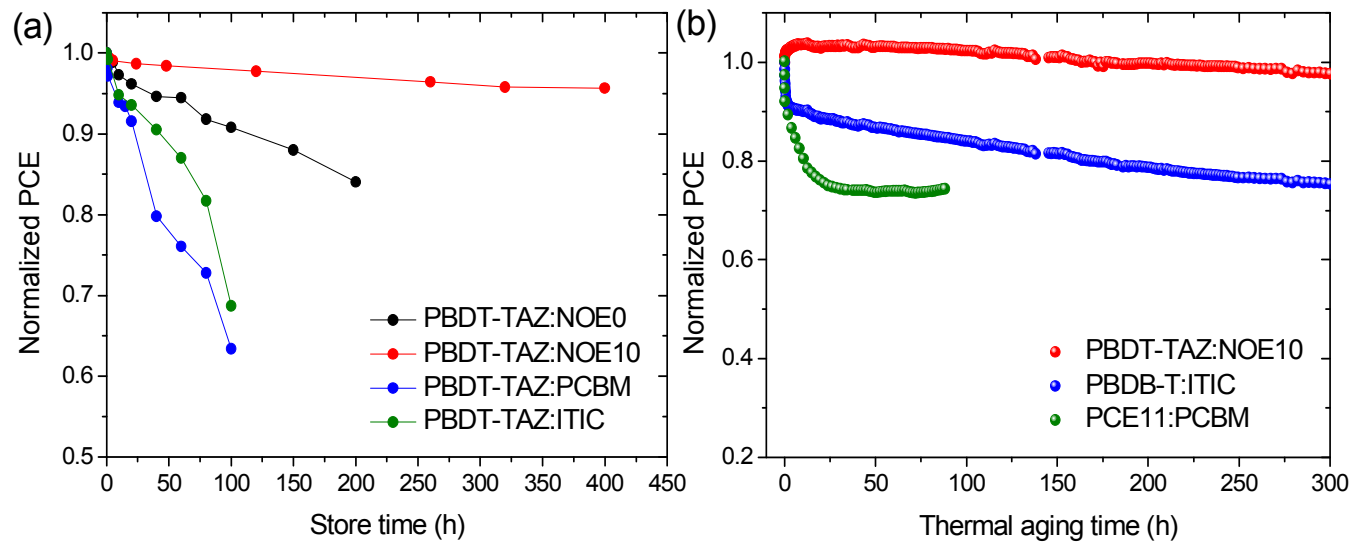

Figure 10. (a) Normalized PCE for storage lifetime of the solar cells made from the same donor polymer PBDT-TAZ but different acceptors (NOEo, NOE1o, PCBM, and ITIC) in nitrogen-fill glovebox under dark; (b) normalized device performance based on PBDT-TAZ:NOE1o, PBDB-T:ITIC, and PCE11:PCBM over the $65^{\circ} \mathrm{C}$ thermal aging time in the dark.

\section{- CONCLUSION}

In conclusion, we synthesized a series of NDI-based conjugated polymers (NOEx) modified with different contents of OE chains with the intention to fine-tune the 
morphology and nanostructures of the resulting polymer:polymer BHJ blends. With $10 \%$ of OE side chains, NOEı shows an increase of miscibility with polymer donor compared to NOEo, which renders the NOE1o-based blend film with improved polymer packing, nano-phase separation, and vertical phase gradation. As a result, the best all-PSCs based on the NOE1o show a PCE of $8.1 \%$ with a $J_{\mathrm{sc}}$ of $12.9 \mathrm{~mA} \mathrm{~cm}{ }^{-2}$ and a record high FF of 0.75 . Relevant to practical applications, the all-PSCs based on NOEı show excellent storage lifetime and thermal stability with $>97 \%$ of the initial PCE after 300 hours aging at $65{ }^{\circ} \mathrm{C}$. Indeed, NOEıo offers higher device performance than the commercial acceptor polymer N2200 when blended with different donor polymers. Our work demonstrates an effective strategy for forming optimal blend film morphology for all-PSCs, and also shows the excellent potential of NOEıo as an alternative to commercial acceptor polymer for future technological applications.

\section{- ASSOCIATED CONTENT}

\section{Supporting Information}

Experimental details, synthetic route, GPC plots, absorption spectra, CV curves, views of surface contact measurements, PL spectra, GIWAXS patterns, RSoXS curves, FT-IR spectra, and additional tables. These materials are available free of charge via the Internet at http://pubs.acs.org.

\section{- AUTHOR INFORMATION}

\section{Corresponding Author}


C. D. (duanchunhui@scut.edu.cn)

F. L. (fengliu82@sjtu.edu.cn)

F. H. (msfhuang@scut.edu.cn)

\section{Notes}

The authors declare non competing financial interests.

\section{- ACKNOWLEDGMENTS}

The research was financially supported by the Recruitment Program of Global Youth Experts of China. This work was also supported by the Ministry of Science and Technology (Nos. 2017YFAo2066oo, 2014CB643501), and the Natural Science Foundation of China (No. 21634004, Nos. 21520102006 and 91633301). N.L. gratefully acknowledges the financial support from the DFG research grant: BR 4031/13-1, and the Bavarian Ministry of Economic Affairs and Media, Energy and Technology by funding the HI-ERN (IEKı1) of FZ Jülich. C.J.B. gratefully acknowledges the financial support through the "Aufbruch Bayern" initiative of the state of Bavaria (EnCN and "Solar Factory of the Future"), the Bavarian Initiative "Solar Technologies go Hybrid" (SolTech) and the SFB 953 (DFG). C.Z. would like to acknowledge the financial support from the China Scholarship Council (CSC) and the Bavarian Initiative "Solar Technologies go Hybrid" (SolTech). M.L. acknowledges the funding from the European Union's Horizon 2020 research and innovation programme under the Marie Skłodowska-Curie grant agreement No. 747422. R.A.J.J. acknowledges funding from the European Research Council under the European Union's Seventh Framework Programme 
(FP/2007-2013)/ERC Grant Agreement No. 339031. X.L. thanks the China Scholarship

Council (CSC) for financial support.

\section{- REFERENCES}

(1) Facchetti, A. Mater. Today 2013, 16, 123.

(2) Kang, H.; Lee, W.; Oh, J.; Kim, T.; Lee, C.; Kim, B. J. Acc. Chem. Res. 2016, 49, 2424.

(3) Root, S. E.; Savagatrup, S.; Printz, A. D.; Rodriquez, D.; Lipomi, D. J. Chem. Rev. 2o17, 117,6467 .

(4) (a) Benten, H.; Mori, D.; Ohkita, H.; Ito, S. J. Mater. Chem. A 2016, 4, 5340. (b) Zhang, X. Acta Polym. Sin. 2018, 2, 129. (c) Song, C.-P.; Qu, Y.; Liu, J.-G.; Han, Y.-C. Acta Polym. Sin. 2018, 2, 145.

(5) (a) Gao, L.; Zhang, Z.-G.; Xue, L.; Min, J.; Zhang, J.; Wei, Z.; Li, Y. Adv. Mater. 2o16, 28, 1884. (b) Guo, Y.; Li, Y.; Awartani, O.; Han, H.; Zhao, J.; Ade, H.; Yan, H.; Zhao, D. Adv. Mater. 2017, 29, 1700309. (c) Zhang, Z.-G.; Yang, Y.; Yao, J.; Xue, L.; Chen, S.; Li, X.; Morrison, W.; Yang, C.; Li, Y. Angew. Chem. Int. Ed. 2017, 56, 13503. (d) Fan, B.; Ying, L.; Wang, Z.; He, B.; Jiang, X.; Huang, F.; Cao, Y. Energy Environ. Sci. 2o17, 10, 1243. (e) Li, Z.; Xu, X.; Zhang, W.; Meng, X.; Genene, Z.; Ma, W.; Mammo, W.; Yartsev, A.; Andersson, M. R.; Janssen, R. A. J.; Wang, E. Energy Environ. Sci. 2017, 10, 2212. (f) Fan, B.; Ying, L.; Zhu, P.; Pan, F.; Liu, F.; Chen, J.; Huang, F.; Cao, Y. Adv. Mater. 2017, 1703906. (g) Chen, D.; Yao, J.; Chen, L.; Yin, J.; Lv, R.; Huang, B.; Liu, S.; Zhang, Z.-G.; Yang, C.; Chen, Y.; Li, Y. Angew. Chem. Int. Ed. 2o18, 57, 4580. (h) Li, Z.; Fan, B.; He, B.; Ying, L.; Zhong, W.; Liu, F.; Huang, F.; Cao, Y. Sci. China Chem. 2o18, 61, 427. (i) Fan, B.; Zhu, P.; Xin, J.; Li, N.; Ying, L.; Zhong, W.; Li, Z.; Ma, W.; Huang, F.; Cao, Y. Adv. Energy Mater. 2018, 1703085. (6) (a) Zhao, W.; Li, S.; Yao, H.; Zhang, S.; Zhang, Y.; Yang, B.; Hou, J. J. Am. Chem. Soc. 2017, 139, 7148. (b) Zhang, S.; Qin, Y.; Zhu, J.; Hou, J. Adv. Mater. 2018, 1800868.

(7) Li, Z.; Xu, X.; Zhang, W.; Meng, X.; Ma, W.; Yartsev, A.; Inganäs, O.; Andersson, M. R.; Janssen, R. A. J.; Wang, E. J. Am. Chem. Soc. 2016, 138, 10935.

(8) (a) Kang, H.; Uddin, M. A.; Lee, C.; Kim, K.-H.; Nguyen, T. L.; Lee, W.; Li, Y.; Wang, C.; Woo, H. Y.; Kim, B. J. J. Am. Chem. Soc. 2015, 137, 2359. (b)Li, Z.; Zhang, W.; Xu, X.; Genene, Z.; Rasi, D. D. C.; Mammo, W.; Yartsev, A.; Andersson, M. R.; Janssen, R. A. J.; Wang, E. Adv. Energy Mater. 2017, 7, 1602722.

(9) (a) Jung, J. W.; Jo, J. W.; Chueh, C.-C.; Liu, F.; Jo, W. H.; Russell, T. P.; Jen, A. K.-Y. Adv. Mater. 2015, 27, 3310. (b) Hwang, Y.-J.; Courtright, B. A. E.; Ferreira, A. S.; Tolbert, S. H.; Jenekhe, S. A. Adv. Mater. 2015, 27, 4578. (c) Oh, J.; Kranthiraja, K.; Lee, C.; Gunasekar, K.; Kim, S.; Ma, B.; Kim, B. J.; Jin, S.-H. Adv. Mater. 2016, 28, 10016. (d) Kim, T.; Kim, J.-H.; Kang, T. E.; Lee, C.; Kang, H.; Shin, M.; Wang, C.; Ma, B.; Jeong, U.; Kim, 
T.-S.; Kim, B. J.; Nat. Commun. 2015, 6, 8547. (e) Shi, S.; Yuan, J.; Ding, G.; Ford, M.; Lu, K.; Shi, G.; Sun, J.; Ling, X.; Li, Y.; Ma, W. Adv. Funct. Mater. 2016, 26, 5669. (f) Li, K.; Xie, R.; Zhong, W.; Lin, K.; Ying, L.; Huang, F.; Cao, Y. Sci. China Chem. 2o18, 61, 576.

(10) (a) Zhan, X.; Tan, Z.; Domercq, B.; An, Z.; Zhang, X.; Barlow, S.; Li, Y.; Zhu, D.; Kippelen, B.; Marder, S. R. J. Am. Chem. Soc. 2007, 129, 7246. (b) Guo, Y.; Li, Y.; Awartani, O.; Zhao, J.; Han, H.; Ade, H.; Zhao, D.; Yan, H. Adv. Mater. 2o16, 28, 8483. (c) Li, S.; Zhang, H.; Zhao, W.; Ye, L.; Yao, H.; Yang, B.; Zhang, S.; Hou, J. Adv. Energy Mater. 2o16, 6, 1501991. (d) Xiong, W.-T.; Guo, Y.-K.; Zhao, D.-H.; Sun, Y.-M. Acta Polym. Sin. 2018, 2, 315.(11) Wang, Y.; Yan, Z.; Guo, H.; Uddin, M. A.; Ling, S.; Zhou, X.; Su, H.; Dai, J.; Woo, H. Y.; Guo, X. Angew. Chem. Int. Ed. 2017, 56, 15304.

(12) Long, X.; Ding, Z.; Dou, C.; Zhang, J.; Liu, J.; Wang, L. Adv. Mater. 2016, 28, 6504.

(13) Liu, S.; Firdaus, Y.; Thomas, S.; Kan, Z.; Cruciani, F.; Lopatin, S.; Bredas, J.-L.; Beaujuge, P. M. Angew. Chem. Int. Ed. 2018, 57, 531.

(14) Yan, H.; Chen, Z.; Zheng, Y.; Newman, C.; Quinn, J. R.; Dötz, F.; Kastler, M.; Facchetti, A. Nature 2009, 457, 679.

(15) (a) Chang, W.-H.; Gao, J.; Dou, L.; Chen, C.-C.; Liu, Y.; Yang, Y. Adv. Energy Mater. 2014, 4, 1300864. (b) Meng, B.; Song, H.; Chen, X.; Xie, Z.; Liu, J.; Wang, L. Macromolecules 2015, 48, 4357. (c) Chen, X.; Zhang, Z.; Ding, Z.; Liu, J.; Wang, L. Angew. Chem. Int. Ed. 2016, 55, 10376. (d) Liu, X.; Xie, B.; Duan, C.; Wang, Z.; Fan, B.; Zhang, K.; Lin, B.; Colberts, F. J. M.; Ma, W.; Janssen, R. A. J.; Huang, F.; Cao, Y. J. Mater. Chem. A 2018, 6, 395 .

(16) The synthesis of this polymer will be published elsewhere.

(17) (a) Bartesaghi, D.; Pérez, I. d. C.; Kniepert, J.; Roland, S.; Turbiez, M.; Neher, D.; Koster, L. J. A. Nat. Commun. 2015, 6, 7083. (b) Gasparini, N.; Jiao, X.; Heumueller, T.; Baran, D.; Matt, G. J.; Fladischer, S.; Spiecker, E.; Ade, H.; Brabec, C. J.; Ameri, T. Nat. Energy 2016, 1, 16118.

(18) Scharber, M. C.; Mühlbacher, D.; Koppe, M.; Denk, P.; Waldauf, C.; Heeger, A. J.; Brabec, C. J. Adv. Mater. 2oo6, 18, 789.

(19) Zhang, C.; Mumyatov, A.; Langner, S.; Perea, J. D.; Kassar, T.; Min, J.; Ke, L.; Chen, H.; Gerasimov, K. L.; Anokhin, D. V.; Ivanov, D. A.; Ameri, T.; Osvet, A.; Susarova, D. K.; Unruh, T.; Li, N.; Troshin, P.; Brabec, C. J. Adv. Energy Mater. 2017, 7, 1601204.

(20) Owens, D. K.; Nemours E. I.; Film, S. J. Appl. Polym. Sci. 1969, 13, 1741.

(21) (a) Grulke, E. A. in Polymer Handbook (4th Edition), (Eds: Brandrup, J.; Immergut, E. H.; Grulke, E. A.), Wiley, New York, USA 1999, p. 675. (b) Kouijzer, S.; Michels, J. J.; Berg, M. v. d.; Gevaerts, V. S.; Turbiez, M.; Wienk, M. M.; Janssen, R. A. J. J. Am. Chem. Soc. 2013, 135, 12057. (c) Franeker, J. J. v.; Hermida-Merino, D.; Gommes, C.; Arapov, K.; Michels, J. J.; Janssen, R. A. J.; Portale, G. Adv. Funct. Mater. 2017, 27, 1702516. (d) Nilsson, S.; Bernasik, A.; Budkowski, A.; Moons, E. Macromolecules 2007, 40, 8291. (22) Koster, L. J. A.; Smits, E. C. P.; Mihailetchi, V. D.; Blom, P. W. M. Phys. Rev. B 2005, 
$72,085205$.

(23) Cowan, S. R.; Roy, A.; Heeger, A. J. Phys. Rev. B 2010, 82, 245207.

(24) Rajapaksa, I.; Uenal, K.; Wickramasinghe, H. K. Appl. Phys. Lett. 2010, 97, 073121.

(25) (a) Jahng, J.; Fishman, D. A.; Park, S.; Nowak, D. B.; Morrison, W. A.; Wickramasinghe, H. K.; Potma, E. O. Acc. Chem. Res. 2015, 48, 2671. (b) Qiu, B.; Xue, L.; Yang, Y.; Bin, H.; Zhang, Y.; Zhang, C.; Xiao, M.; Park, K.; Morrison, W.; Zhang, Z.-G. Li, Y. Chem. Mater. 2017, 29, 7543. (c) Gu, K. L.; Zhou, Y.; Morrison, W. A.; Park, K.; Park, S.; Bao, Z. ACS Nano 2018, 12, 1473.

(26) (a) Zhang, C.; Mumyatov, A.; Langner, S.; Perea, J. D.; Kassar, T.; Min, J.; Ke, L.; Chen, H.; Gerasimov, K. L.; Anokhin, D. V.; Ivanov, D. A.; Ameri, T.; Osvet, A.; Susarova, D. K.; Unruh, T.; Li, N.; Troshin, P.; Brabec, C. J. Adv. Energy Mater. 2017, 7, 1601204. (b) Li, N.; Perea, J. D.; Kassar, T.; Richter, M.; Heumueller, T.; Matt, G. J.; Hou, Y.; Güldal, N. S.; Chen, H.; Chen, S.; Langner, S.; Berlinghof, M.; Unruh, T.; Brabec, C. J. Nat. Commun. 2017, 8, 14541.

(27) (a) Zhao, W.; Qian, D.; Zhang, S.; Li, S.; Inganäs, O.; Gao, F.; Hou, J. Adv. Mater. 2016, 28, 4734. (b) Liu, Y. H.; Zhao, J. B.; Li, Z. K.; Mu, C.; Ma, W.; Hu, H. W.; Jiang, K.; Lin, H. R.; Ade, H.; Yan, H. Nat. Commun. 2014, 5, 5293. 


\section{TOC}

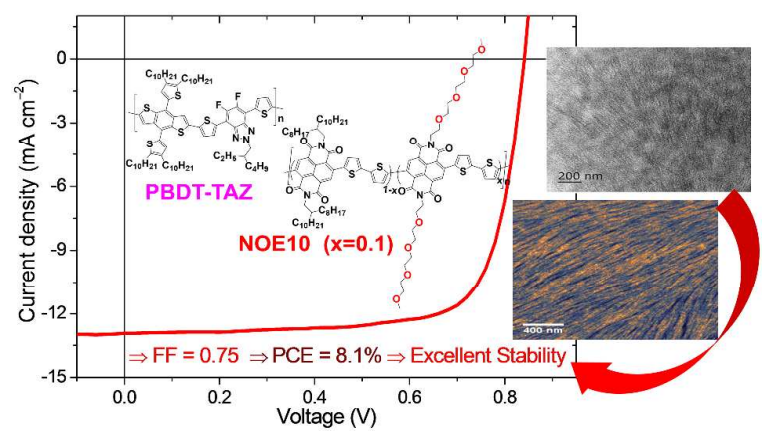

